\title{
¿UNA NUEVA FORMA DE GOBERNAR? \\ MODELO HEURÍSTICO PARA ANALIZAR LA PARTICIPACIÓN CIUDADANA EN LA GESTIÓN PÚBLICA
}

\author{
Laura Beatriz Montes de Oca Barrera \\ Universidad Nacional Autónoma de México \\ lbmontesdeoca@sociales.unam.mx
}

\section{RESUMEN}

A partir del análisis de tres espacios consultivos, considerados innovaciones gubernamentales y que operaron durante la administración pública federal de México entre 2011 y 2015, el artículo propone una discusión teórica entre los enfoques de la gobernanza, el gobierno abierto y las innovaciones democráticas. Desde estos enfoques se habla de una nueva forma de gobernar y se construye un modelo heurístico describiendo sus componentes analíticos y variables. En la discusión y construcción del modelo, el artículo busca incluir la dimensión política, considerada de manera insuficiente en los enfoques referidos, la cual incluye relaciones de poder (y sus dos dimensiones, el control y la influencia), así como conflicto en la arena pública.

Palabras clave: Gobierno abierto, Innovación democrática, Consejos consultivos, Participación, México. 


\title{
A NEW WAY OF GOVERNING? \\ A HEURISTIC MODEL FOR ANALYZING PUBLIC \\ PARTICIPATION IN ADMINISTRATION OF THE STATE
}

\begin{abstract}
Based on the analysis of three spaces of consultation, which operated as part of federal state administration in Mexico between 2011 and 2015 and were considered government innovations, the paper presents a theoretical discussion of two approaches to governance: open government and democratic innovations. Based on these approaches, it discusses a new form of government and constructs a heuristic model describing its analytical components and variables. In the discussion and construction of the model, the paper seeks to include the political dimension, which is not taken into account sufficiently in the approaches indicated, which includes power relations (and their two dimensions: control and influence) as well as conflict in the public arena.
\end{abstract}

Keywords: Open government, Democratic innovation, Consultative councils, Participation, Mexico. 


\title{
INTRODUCCIÓN
}

\begin{abstract}
My Administration is committed to creating an unprecedented level of openness in Government. We will work together to ensure the public trust and establish a system of transparency, public participation, and collaboration. Openness will strengthen our democracy and promote efficiency and effectiveness in Government (Obama 2009).
\end{abstract}

Las palabras que inauguraron la presidencia estadounidense de Barack Obama en 2009 están estrechamente relacionadas con las discusiones recientes sobre la relación gobierno-ciudadanía, condensadas en las teorías del gobierno abierto, las innovaciones democráticas y la gobernanza, desde las cuales se habla de una nueva forma de gobernar al incluir principios y prácticas como la transparencia, la participación y la colaboración en la gestión pública ${ }^{1}$. En este artículo se propone contrastar estas propuestas teóricas a fin de construir un modelo heurístico que permita valorar, en casos específicos, si se está cristalizando un nuevo proceder gubernamental en México.

Para ello se problematizan los "silencios" conceptuales de estas aproximaciones analíticas, en particular, en lo referente al componente político; esto es, al ámbito de las relaciones de poder y sus dos dimensiones, el control y la influencia; así como respecto a la relevancia del conflicto en la arena pública. Elementos de las discusiones sobre poder e influencia política, pueden ser útiles para sacar del silencio esta dimensión y apuntalar un modelo analítico que incorpore no solo los componentes propuestos por los tres campos teóricos referidos -transparencia, participación y colaboración-, sino que incluya el componente político y, con ello, el equilibrio entre el control estatal y la influencia externa en la toma de

1 Aquí cabe hacer mención de las rupturas y continuidades en el estudio de la gestión pública (Ozslak 2016: 38) -que van desde la antigua Administración Científica hasta el más reciente New Public Management y uno de sus epígonos: el enfoque del servicio público. En particular el enfoque del servicio público "se basa en siete principios sinérgicos: servir a ciudadanos, no a clientes; procurar el interés público; valorizar la ciudadanía, o el empresarismo; pensar estratégicamente; actuar democráticamente; no dar por sentada la rendición de cuentas; servir en lugar de dirigir; valorizar a la gente, no a la productividad" (Ozslak 2016: 43). No es difícil percibir los paralelismos entre estos principios y lo propuesto en las discusiones sobre gobierno abierto, innovaciones democráticas y gobernanza. 
decisión pública.

En la primera parte del texto se abunda sobre esta problematización y discusión teórica; en la segunda se expone el modelo heurístico describiendo sus componentes analíticos y variables. En la tercera parte del artículo, se aplica este modelo para analizar -a manera de ejemplo- una innovación gubernamental que ha sido reconocida como un intento por transformar la gestión pública con base en principios como transparencia, participación y colaboración (PNUD 2017), pero también ampliamente criticada, en la literatura especializada mexicana: los consejos consultivos (Hevia 2012, Hevia e Isunza 2012, Montes de Oca 2012, 2014).

En particular se presenta el análisis de tres casos de estudio que operaron durante la administración pública federal mexicana entre 2011 y 2015: 1) el Consejo Consultivo de la extinta Comisión Federal de Telecomunicaciones (CCCft); 2) el Consejo Consultivo del Consumo, dependiente de la Procuraduría Federal del Consumidor (CCC); así como, 3) el Comité Consultivo Nacional de Normalización de Seguridad al Usuario, Información Comercial y Prácticas de Comercio, adscrito a la Secretaría de Economía (CCNN).

Este análisis tiene una finalidad triple. Primero, integrar la dimensión política en el análisis de espacios de participación que siguen, formalmente, los principios del gobierno abierto, las innovaciones democráticas y la gobernanza. Segundo, mostrar la forma en que se puede aplicar el modelo construido; y, tercero, valorar si estos espacios constituyen una nueva forma de interacción entre gobernantes y gobernados, lo cual es discutido en las conclusiones.

\section{PLANTEAMIENTO DEL PROBLEMA Y DISCUSIÓN TEÓRICA} INNOVACIONES DEMOCRÁTICAS, GOBIERNO ABIERTO Y GOBERNANZA

Recientemente, en las teorías sobre la democracia se ha abierto un nuevo campo de discusión: el de las innovaciones democráticas. Con ello se hace referencia a los experimentos gubernamentales orientados a reforzar la participación de la ciudadanía en el proceso gubernamental y los procesos decisorios (Grindle 2000, Welp y Whitehead 2011, Cameron, Hershberg y Sharpe 2012, Fung y Wright 2003, Smith 2009). Formalmente se plantea que estos experimentos están orientados a complementar y profundizar la democracia representativa y, con ello, a democratizar la gestión y la toma de decisión pública.

Este planteamiento implica reconsiderar la clásica oposición entre 
democracia representativa y participativa (véase, por ejemplo, Sartori 2003); y, en su lugar, se propone su complementariedad (Welp y Whitehead 2011, Alonso, Keane y Merkel 2011). En términos de la relación agente-principal, se plantearía entonces que el ejercicio representativo, en manos de los gobernantes (agente), se complementa con instrumentos de transparencia equilibrando la información con la que cuentan los ciudadanos (principal). Pero la transparencia no es suficiente; se requieren, además, instrumentos de participación, colaboración e influencia que, en última instancia, doten al ciudadano de mayor capacidad de agencia, lo cual se traduciría en una amplia democratización de los procesos gubernamentales y decisorios.

La discusión sobre innovaciones democráticas, centrada en propuestas para mejorar la práctica democrática, encuentra otros paralelos analíticos como el planteamiento sobre las innovaciones sociales y las innovaciones públicas (Zurbriggen y González 2014), con el que se proponen ejercicios de gestión compartida en la relación gobierno-sociedad-mercado para la co-creación de políticas y servicios públicos. Mientras la propuesta de innovación democrática implica el establecimiento de espacios y mecanismos de participación dentro de la estructura gubernamental (como en consejos consultivos, oficinas de contraloría social o bien mediante consultas públicas y presupuestos participativos), las innovaciones públicas y sociales implican la formación de nuevos espacios y mecanismos de co-creación fuera de la estructura gubernamental, en los que participen de manera colaborativa agentes públicos y privados. De ahí que aquí se distingan las innovaciones democráticas gubernamentales (como los consejos consultivos) de las innovaciones sociales y públicas (como los laboratorios de innovación social en países nórdicos o bien, en el continente americano, con programas y centros de innovación social que incluyen la participación activa y colaborativa de agentes del mercado, la sociedad civil y el gobierno).

Ahora bien, hablar de transparencia, participación y colaboración nos lleva a otra discusión en Ciencia Política y Administración Pública: la del gobierno abierto (open government). Este concepto ocupó la atención desde la década de los cincuenta para referirse al secreto del gobierno y a la necesidad de abrirse al ciudadano (Campos y Corojan 2012, Ozslak 2016, Valenzuela 2014); empero, no tuvo mayor trascendencia sino hasta la primera década del siglo XXI con la propuesta del presidente estadounidense Barak Obama para fortalecer la democracia y mejorar la eficiencia y eficacia gubernamentales. Después de ello el concepto escaló a la escena internacional con la Alianza para el Gobierno Abierto (Open 


\section{Government Partnership) $)^{2}$.}

En términos conceptuales, se define como gobierno abierto aquel que impulsa la transparencia para la rendición de cuentas; promueve la participación para mejorar la eficacia gubernamental; además de que induce la colaboración al incorporar ciudadanos en la acción del gobierno (Valenzuela 2014, Mariñez 2013, Ozslak 2016). Para ello, el gobierno abierto se cimienta en dos principios rectores: la comunicación y la coordinación (Villoria 2012). Desde que se empleó por primera vez en la década de los cincuenta, este concepto ha evolucionado: a partir una mirada que apela a forjar una administración pública transparente, accesible y receptiva, se transformó en una propuesta que implica construir estrategias gubernamentales de trabajo conjunto con la sociedad a fin de crear valor público (Güemes y Ramírez 2012, Moore 2006, Ozslak 2016).

Ahora bien, a pesar de que un rasgo particular del gobierno abierto es el aprovechamiento de las tecnologías de la información y la comunicación para articular transparencia, participación y colaboración, este se distingue del gobierno electrónico porque implica transformaciones organizacionales más amplias; las cuales se traducen en una "nueva forma de gobernar" (Campos y Corjan 2012, Calderón 2012); así como en una nueva forma de interacción de la ciudadanía con el gobierno (Martínez 2012); y, en última instancia, una nueva forma en que el Estado funciona (Ozslak 2016).

El gobierno electrónico refiere al uso y aplicación "casi mecánica de las herramientas tecnológicas en los servicios públicos para mejorar procesos y servicios", conservando una postura unilateral y cerrada hacia afuera; $y$ vislumbrando al ciudadano como un usuario, beneficiario o cliente pasivo. En contraste, la propuesta del gobierno abierto busca una transformación más radical que trasciende las fronteras de lo estatal y la aplicación tecnológica; y que implica replantear la administración y el gobierno, sus valores, procedimientos y dogmas (Güemes y Ramírez 2012: 203,

2 Esta alianza fue lanzada el 20 de septiembre de 2011 por ocho gobiernos (Brasil, Indonesia, México, Noruega, Filipinas, Sudáfrica, Reino Unido y Estados Unidos de América) para promover en la práctica gubernamental, a escala global, mayor transparencia, combate a la corrupción y uso de las tecnologías para fortalecer la gestión pública (Ozslak 2016). Desde su fundación, esta alianza ha crecido a 79 países y 20 miembros locales que trabajan junto a miles de organizaciones de la sociedad civil para desarrollar proyectos específicos con miras a obtener resultados positivos en cuanto la mejora de los servicios públicos, el aumento de la confianza en las instituciones y la creación de valor para los ciudadanos (https://www. opengovpartnership.org/our-members/). 
Calderón 2012: 28). Bajo esta óptica, la ciudadanía se convierte en uno de los pilares que hacen funcionar el sistema político-gubernamental.

Lo anterior refiere una transformación de la "visión internista" de la administración pública, confiriéndole un lugar central al ciudadano (Aguilar 2006: 43-45). Ello se traduce en un cambio en el papel del ciudadano: de ser un agente pasivo en algunos casos, o reactivo en otros, se convierte en uno activo y propositivo. De entablarse una interacción entre gobernantes y súbditos, o una donde los gobernantes son advertidos como rivales, se establece una interacción entre aliados. Esto implica hacer las cosas de manera distinta en dos ámbitos interrelacionados: el gubernamental y el de la ciudadanía ${ }^{3}$. Se requieren cambios organizacionales y culturales de tipo funcional, estructural, comportamental y relacional (Cabrero y Arellano 1993) para generar transformaciones dentro del gobierno, en la relación gobierno-entorno y en la propia ciudadanía ${ }^{4}$.

Estos cambios se traducen en una reorganización administrativa, por un lado; y en una renovación ciudadana, por el otro. Lo primero se cristaliza en la reducción de los niveles jerárquicos dentro del gobierno; la descentralización de las decisiones; la creación de agencias especializadas autónomas; la orientación de la acción administrativa hacia el ciudadano (usuario del servicio público); la transversalidad administrativa; así como la certificación de procesos. Lo segundo implica una transformación en la relación del ciudadano con el gobierno, dejando atrás las inercias clientelares o de confrontación; y, en su lugar, propiciando la deliberación pública, la corresponsabilidad ciudadana y el interés por exigir cuentas al gobierno (Aguilar 2006).

Al hablar de estas transformaciones entramos en otra discusión que ocupa cada vez más páginas de libros especializados: la gobernanza como una nueva fórmula de articulación e influencia mutua entre agentes

3 Así como el ámbito gubernamental no es cerrado o monolítico, pero tampoco es un espacio desordenado y atomizado (Arellano y Cabrero 2000), aquí se plantea que el ámbito ciudadano tiene las mismas características. Los dos están conformados como entes heterogéneos "de múltiples partes (actores, políticos, leyes, reglas, tiempos, [intereses], etcétera) pero que se relacionan y condicionan de una forma continua” (Arellano y Cabrero 2000: 15).

4 En resumidas cuentas, el cambio funcional corresponde a reformas administrativas y nuevos marcos normativos; el estructural a la descentralización de la toma de decisión; el comportamental al cambio de actitud hacia la cooperación; y el relacional a nuevas formas de interacción con el entorno (Cabrero y Arellano 1993, véase también Arellano y Amaya 2000). 
gubernamentales, sociales y económicos (Kooiman 1993, 2003, Pierre 2000, Pierre y Peters 2000); como una nueva forma de gobernar, diferente al control jerárquico del Estado o el mercado (Mayntz 2005). Esto es posible porque el proceder de la gobernanza, sustituyendo al "tradicional" gobierno centralizado -que sigue una lógica top-down-, está basado en la negociación, coordinación y persuasión (Cerrillo 2005); ya sea mediante la articulación de redes público-privadas (Mayntz 2005); o bien, como una configuración interorganizacional (Kooiman 2003). En términos de agencia-estructura, una gobernanza menos controlada -es decir, más abierta en la estructura de interacción- permite mayor posibilidad de negociación y coordinación entre los involucrados considerando sus objetivos, intereses y valores (Kooiman 2003: 63-64).

Es preciso aquí enfatizar que este concepto tampoco es nuevo. Fue empleado desde principios de la década de los setenta para hacer referencia a teorías prescriptivas de planificación (Santos 2007). En los ochenta fue un recurso para la implementación de las políticas públicas y, particularmente en el ámbito de la cooperación internacional, aparece en un informe del Banco Mundial en 1989 (Mayntz 2005: 84). Como esta genealogía coincide con la implementación de políticas económicas que favorecían la desregulación del mercado y la privatización de empresas estatales, suele atribuírsele un sesgo neoliberal a este nuevo proceder gubernamental. Ya sea vinculándosele con la idea de un Estado mínimo; o bien, con a la aplicación de esquemas gerenciales en la administración pública (Rhodes 2005: 100), en particular con la corriente anglosajona del New Public Management, orientada a mantener el equilibrio de las finanzas públicas (Aguilar 2006: 18). No obstante, Pierre y Peters (2000: 132-133) advierten importantes diferencias entre gobernanza y la Nueva Gestión Pública (sustentada en el gerencialismo $)^{5}$ : la gobernanza mantiene cierto grado del control político sobre el servicio público; está orientada por procesos, no por resultados; obedece a una lógica interorganizacional (no intraorganizacional); además de que la gobernanza no requiere un giro ideológico-neoliberal.

Ahora bien, abundando en las críticas sobre el sesgo neoliberal de la gobernanza, podemos ubicar aquella que la refiere como una innovación jurídica ocurrida dentro de la "globalización neoliberal" y como un "supuesto modo de regulación social posestatal" (Santos 2007: 32). Desde esta

5 La aplicación del gerencialismo en la administración pública, siguiendo a Osborne y Gaebler (1994), se traduce en medir el rendimiento de las agencias gubernamentales a partir de los resultados y no por los ingresos; en guiar los procesos mediante objetivos y no acorde a normas y regulaciones; además de considerar a los ciudadanos como clientes o consumidores (véase también Rhodes 2005: 103-104). 
perspectiva, se equipara la emergencia de la "política neoliberal" producto del diagnóstico de la Comisión Trilateral de 1975, con la implementación de la gobernanza como una estrategia alineada a la descentralización del Estado y a una cuádruple sustitución: 1) de lo político por lo técnico; 2) de la participación popular por los sistemas de expertos; 3) de lo público por lo privado; así como 4) del Estado por el mercado. Esta perspectiva crítica, en particular en lo referente a la cuarta sustitución, parece extrema si revisamos las distintas formulaciones sobre la gobernanza.

En términos generales, el debate sobre la gobernanza no plantea el debilitamiento del Estado, sino su transformación. Refiere, más bien, la descentralización del control político estatal hacia múltiples centros de poder con capacidad de influencia; por lo que la fortaleza del Estado no radica en un control absoluto o casi total sobre la agencia pública, sino en una amplia capacidad para regular, innovar y coordinar. En este sentido, el argumento de que el Estado es uno de los "actores no existentes" en la conceptualización sobre la gobernanza (Santos 2007: 34) no se sostiene ${ }^{6}$. Hasta en las formulaciones más conservadoras, el Estado -si bien diluidono desaparece; es el garante de una "gerencia técnicamente eficiente" (Torres y Ramos 2012: 109).

Trascendiendo estas formulaciones reduccionistas (en contra y a favor) que no agotan las propuestas teóricas de la gobernanza ${ }^{7}$, las más recientes definiciones buscan entender la gobernanza como la coordinación y la construcción de acuerdos y diálogos locales instrumentados a través de redes de políticas públicas, rendición de cuentas y participación ciudadana (Torres y Ramos 2012: 108-109). Ahí el Estado tiene un papel relevante como regulador. Es decir, como una autoridad que, mediante agencias autónomas, regula las relaciones del mercado (Jordana y Levi-Faur 2004, Cofemer 2012).

Considerando estos argumentos y para concluir este apartado encontramos que pensar en clave de innovaciones democráticas, de gobierno abierto y de gobernanza no elimina al gobierno o a la autoridad estatal de la ecuación, sino que descentraliza su posición en la relación

6 En todo caso, este argumento solo se aplicaría a las propuestas apegadas al economicismo que vislumbran en el Estado la causa de todos los males -sociales, políticos y económicos- y, por ello, promueven una imagen -desde mi perspectiva desvirtuada- de la gobernanza como un gobierno sin Estado.

7 La gobernanza "tampoco es la fórmula que la política esperaba [...] como salvación del mal social y la creación de un mundo reconciliado” (Aguilar 2006: 24). 
con los demás agentes. Lo que estas discusiones resaltan es la importancia de que el gobierno transforme la gestión pública mediante prácticas de transparencia, participación y colaboración. Estas prácticas, empero y como se verá enseguida, no se traducen en una vinculación armónica. De ahí la necesidad de ampliar la conceptualización incluyendo el componente político.

MÁS ALLÁ DE LA COOPERACIÓN: RELACIONES DE PODER Y CONFLICTO

Si retomamos las tres propuestas teóricas discutidas -innovaciones democráticas, gobierno abierto y gobernanza- encontramos que la nueva forma de gobernar nos remite a una fórmula que, a manera de un tipo ideal (Weber 1964), está basada en el acuerdo y la cooperación para alcanzar objetivos compartidos. Esta propuesta, empero, es rebasada por una realidad política caracterizada, en términos generales, por la confrontación de intereses; por la existencia de importantes diferenciales de poder entre los diversos agentes (públicos y privados); y por una casi permanente contienda orientada a obtener más recursos que el contrincante. Una realidad en la que, además, la relación gobernantes-gobernados es complicada debido a que el Estado beneficia a la vez que amenaza; por lo que en un momento se construye un nosotros, mientras en otros se parte de un ellos (Edelman 1967: 1).

Bajo esta lógica resulta insuficiente considerar exclusivamente las tres propuestas teóricas antes descritas para analizar una nueva forma de relación gobierno-ciudadanía. La posibilidad de implementar una buena gobernanza o de hacer democrática una innovación gubernamental ha sido criticada, por ejemplo, por quienes analizan la "comitología" (Shapiro $2003)^{8}$. Desde esta perspectiva se plantea que las decisiones públicas tomadas en ciertas instancias de gobernanza o en innovaciones gubernamentales -semejantes a los consejos consultivos que serán analizados más adelantesuelen ser tomadas por grupos restringidos de expertos; lo que contraviene los principios de apertura y participación de una buena gobernanza, de innovaciones democráticas o de un gobierno abierto?.

Desde las tres propuestas teóricas descritas se omite incluir como

8 La comitología es la puesta en práctica de la gobernanza en consejos y comités con participación de agentes gubernamentales y extragubernamentales.

9 Estos principios refieren a la apertura institucional; a la inclusión y pluralidad en la toma de decisión; así como a la construcción de una agenda compartida y amplia, regida por la deliberación entre una diversidad de voces (Comisión Europea 2001, Montes de Oca 2014). 
parte de la discusión -o se le simplifica- el papel que tienen el control estatal (o gubernamental) y la influencia de agentes externos o grupos de interés (Ornstein y Elder 1978). Si bien, en estas discusiones se habla de influencia mutua, se le piensa normativa o prescriptivamente en términos colaborativos y no como fuente de posibles conflictos de interés. Esto remite nuevamente a la crítica sobre los "silencios más importantes dentro de la matriz de gobernanza": las relaciones de poder y conflicto social (Santos 2007: 36).

Esta desvinculación de lo político genera propuestas que buscando ser asépticas, se alejan tanto de la realidad, que tienen poca utilidad analítica. En esto, aquí se coincide con quienes plantean que "la administración y la política no se pueden separar como áreas distintas de análisis, sino que connotan dos caras de un mismo asunto" (Del Castillo 2000: 381).

Es por ello que aquí se plantea repensar la gobernanza, el gobierno abierto y las innovaciones democráticas como una relación basada en la cooperación de los grupos involucrados, pero también en la imbricación y contraposición de grupos en conflicto. Para ello resulta necesario incorporar la dimensión política al definir la relación gobierno-ciudadanía como una "marcada interdependencia entre los intereses de grupos sociales en conflicto" (Lehmbruch 1992: 69). En específico, se trata de problematizar la idea de una nueva forma de gobernar incluyendo el componente político a través de las dos dimensiones del poder: el control y la influencia; fuentes, en sí mismas, de conflicto y relaciones verticales.

Retomando algunas premisas de las teorías del poder y la influencia (Knoke 1990, Foucault 1988, 1979, Elias 1982, Emerson 1962), el control se define como la capacidad que tiene un actor para la acción y decisión; mientras que la influencia es posible cuando la información transmitida intencionalmente por otro actor es recibida por el primero provocando una alteración en su acción o toma de decisión. En otros términos, podríamos decir que $B$ emite información de manera intencional al tomador de decisión A, quien recibe y, en su caso, acepta esta información modificando su acción o decisión (véase Figura 1). Ello genera que A ceda control frente a la influencia de B. 
Figura 1: Influencia

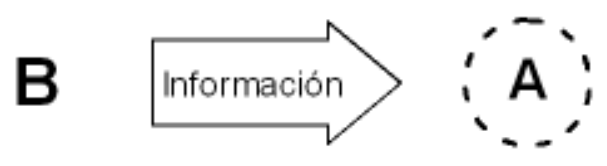

Fuente: Elaboración propia

Desde esta perspectiva el conflicto juega un papel clave para explicar las relaciones de poder de la realidad política (Laumann y Knoke 1987). Por una parte, considerando la posición ocupada en los escenarios decisorios, los agentes extragubernamentales pueden tener mayor o menor capacidad de influencia para posicionar ciertos intereses. Por otra parte, esta realidad también está permeada por el conflicto que conlleva la posible pérdida de control estatal sobre las decisiones y los procesos públicos frente al avance, cada vez más veloz, de la influencia de agentes externos. En suma, poner el foco de atención analítica en el conflicto posibilita situar el lugar desde el que se mantiene el control político sobre los procesos gubernamentales y decisorios; ubicar qué agentes tienen mayor capacidad de influencia en esto; así como identificar los procedimientos de negociación para dirimirlo.

Siguiendo esta veta analítica, la intención del siguiente apartado es presentar un modelo heurístico que, complementando los principales elementos de las propuestas teóricas de las innovaciones democráticas, el gobierno abierto y la gobernanza (transparencia- participacióncolaboración) con el componente político (control-influencia-conflicto), permita construir evidencia empírica para determinar si existe o no una nueva forma de gobernar, en este caso, para innovaciones gubernamentales como los consejos consultivos en México.

El modelo se sustenta en la idea de un gobierno que busca articulaciones horizontales con los agentes externos (en contraposición a uno jerárquico y cerrado); y se le problematiza transformando el tipo ideal -construido desde los principios del gobierno abierto, la gobernanza y las innovaciones democráticas- en un tipo construido, es decir, situado en una arena política caracterizada por diferenciales de poder y por la confrontación de intereses particulares ${ }^{10}$. Esto, en una arena donde la agencia pública (de gobernantes y gobernados) no puede reducirse a la reificación de lo social, el bien común

10 Hablo de tipo construido para referirme a la combinación intencional de un conjunto de criterios con referencias empíricas útiles para el análisis comparativo de casos (Schmitter 1992: 25). 
o el interés público; sino al análisis de los intereses que están en juego y a la lógica de interdependencia que los sustenta (Edelman 1967).

\section{MODELO HEURÍSTICO}

Para construir un modelo heurístico a partir del cual se pueda valorar si una innovación gubernamental favorece una nueva forma de gobernar, se retoman los tres componentes que fundamentan las propuestas teóricas del gobierno abierto, las innovaciones democráticas y la gobernanza (transparencia, participación y colaboración), y se incluye el componente político (control-influencia y el posible conflicto que ello genera) como condiciones de operación y cambio para analizar los dos ámbitos de (inter) acción pública: el gubernamental y el ciudadano (véase Tabla 1$)^{11}$.

\begin{tabular}{|c|c|c|c|}
\hline \multirow[b]{2}{*}{ Transparencia } & Gobierno & Ciudadanía & \\
\hline & $\begin{array}{l}\text { - Disponibilidad de } \\
\text { información para generar } \\
\text { rendimiento o valor público } \\
\text { - Incorporación de } \\
\text { información ciudadana para } \\
\text { la toma de decisión pública }\end{array}$ & $\begin{array}{l}\text { - Aprovechamiento } \\
\text { de la información } \\
\text { gubernamental } \\
\text { - Disponibilidad de } \\
\text { información sobre } \\
\text { actividades propias }\end{array}$ & $\begin{array}{c}\text { Ejercicio } \\
\text { pedagógico de } \\
\text { información }\end{array}$ \\
\hline Participación & $\begin{array}{l}\text { - Apertura de espacios } \\
\text { de participación en } \\
\text { procesos gubernamentales } \\
\text { (innovaciones } \\
\text { gubernamentales) } \\
\text { - Reconocimiento y } \\
\text { aprovechamiento de las } \\
\text { propuestas sociales }\end{array}$ & $\begin{array}{l}\text { - Establecimiento } \\
\text { de espacios propios } \\
\text { de participación } \\
\text { (organizaciones sociales) } \\
\text { - Aprovechamiento } \\
\text { de las innovaciones } \\
\text { gubernamentales }\end{array}$ & $\begin{array}{c}\text { Comunicación } \\
\text { de opiniones }\end{array}$ \\
\hline Colaboración & $\begin{array}{l}\text { - Actitud favorable a la } \\
\text { incorporación de agentes } \\
\text { ciudadanos en los procesos } \\
\text { gubernamentales }\end{array}$ & $\begin{array}{l}\text { - Actitud favorable para } \\
\text { incorporarse a una gestión } \\
\text { pública compartida }\end{array}$ & $\begin{array}{c}\text { Gestión } \\
\text { compartida }\end{array}$ \\
\hline $\begin{array}{l}\text { Control/ } \\
\text { Influencia }\end{array}$ & $\begin{array}{c}\text { - Mecanismos para incorporar } \\
\text { la voz ciudadana en los } \\
\text { procesos decisorios }\end{array}$ & $\begin{array}{c}\text { - Estrategias para incidir } \\
\text { en la toma de decisión } \\
\text { pública }\end{array}$ & $\begin{array}{l}\text { Toma de } \\
\text { decisión } \\
\text { incluyente }\end{array}$ \\
\hline
\end{tabular}

Fuente: Elaboración propia

En lo público convergen agentes sociales, políticos y económicos -cada cual con intereses propios- orientados a influir o controlar los resultados

11 Este modelo es menos ambicioso que el que se requeriría construir para analizar el funcionamiento de las innovaciones sociales o públicas, las cuales trascienden la participación, colaboración e influencia y se centran en la co-creación. Esto último implicaría ejercicios de coordinación público-privada mucho más complejos que los consejos consultivos que ocupan el interés de este artículo. 
políticos. Esto es lo que define la agencia pública; es decir, el control ejercido por actores gubernamentales, así como la capacidad de influencia de agentes sociales y económicos y los posibles conflictos que ello desencadena.

Como se muestra en la Tabla 1, este modelo valora los cambios organizacionales -funcional, estructural, comportamental y relacionalen los dos ámbitos (gubernamental y ciudadano) orientados a reinventar la toma de decisión y gestión públicas. Considerando los componentes que describen una nueva forma de gobernar se analiza la disponibilidad, aprovechamiento e incorporación de información con utilidad pública (transparencia); la apertura y aprovechamiento de innovaciones gubernamentales orientadas a escuchar la voz ciudadana (participación), además del reconocimiento de las propuestas ciudadanas; la actitud favorable hacia la inclusión de agentes externos en el proceso gubernamental (colaboración); así como, la existencia de mecanismos y estrategias que fomenten la incidencia en la toma de decisión pública (influencia).

Estas transformaciones impactan, en conjunto, en la agencia pública al equilibrar el control estatal con la influencia de agentes externos. Con ello se estaría promoviendo: 1) la apertura de información con sentido pedagógico (Martínez 2012), lo cual implica no solo brindar información sino dar herramientas para utilizarla a fin de generar valor público; 2) la posibilidad de externar opiniones sobre el quehacer público; 3) una gestión compartida; así como 4) un ejercicio receptivo para incluir las opiniones vertidas a raíz de la información pública y/o la experiencia de gestión compartida.

Como se aprecia, estos componentes siguen una ruta incremental: para que haya participación es preciso transparencia; para la colaboración son indispensables la transparencia y participación; asimismo, el ejercicio de influencia -que requiere los tres anteriores- implica que el agente decisor ceda control sobre la información, permita la expresión de opiniones y favorezca un trabajo compartido; ello, empero, no implica que se diluya la responsabilidad del tomador de la decisión pública ${ }^{12}$.

Avanzando ahora en la construcción del modelo, se pueden desagregar sus componentes en variables cualitativas.

Como se muestra en la Tabla 2 la transparencia puede ser: reactiva o proactiva; indiscriminada o enfocada (Lee y Kwak 2011); así como

12 Estas etapas encuentran semejanzas con las planteadas por Lee y Kwak (2011) sobre el gobierno abierto: transparencia, consulta, implicación, colaboración y delegación. 
abierta o restringida. La transparencia reactiva e indiscriminada está restringida a grupos específicos (solicitantes), así como a los criterios del oferente (agencias gubernamentales, empresas u organizaciones sociales), quedándose en un plano formal para cumplir un requisito ordenado, en el mejor de los casos, por una disposición legal.

\begin{tabular}{|c|c|c|}
\hline $\begin{array}{l}\text { Componentes } \\
\text { analíticos }\end{array}$ & Variables & Especificación \\
\hline \multirow{6}{*}{$\begin{array}{l}\text { Transparencia } \\
\text { (ejercicio } \\
\text { pedagógico) }\end{array}$} & Reactiva & Frente a petición de parte interesada \\
\hline & Proactiva & Propuesta por el agente responsable \\
\hline & Indiscriminada & $\begin{array}{l}\text { Disposición de información con poca utilidad } \\
\text { pública (solo para cumplir un requisito legal) }\end{array}$ \\
\hline & Enfocada & $\begin{array}{l}\text { Disposición de información valiosa y de alto } \\
\text { impacto sobre temas particulares }\end{array}$ \\
\hline & Abierta & Accesible a todo público interesado \\
\hline & Restringida & Disponible solo para quien la solicite \\
\hline \multirow{6}{*}{$\begin{array}{l}\text { Participación } \\
\text { (ejercicio de } \\
\text { comunicación) }\end{array}$} & Directa & En espacios de interacción cara a cara \\
\hline & Indirecta & A partir de agentes que "representen" los diversos \\
\hline & Abierta & $\begin{array}{l}\text { sectores (sociales, políticos, económicos) } \\
\text { A todo el que esté interesado }\end{array}$ \\
\hline & Restringida & $\begin{array}{l}\text { A partir de una invitación expresa o a una } \\
\text { convocatoria o solicitud que debe ser avalada por la }\end{array}$ \\
\hline & Gubernamental & $\begin{array}{l}\text { Promovida desde el ámbito gubernamental } \\
\text { autrid }\end{array}$ \\
\hline & Extragubernamental & Generada en el ámbito de la ciudadanía \\
\hline \multirow{5}{*}{$\begin{array}{l}\text { Colaboración } \\
\text { (gestión } \\
\text { compartida) }\end{array}$} & Intragubernamental & $\begin{array}{l}\text { Involucra a diversas agencias gubernamentales en la } \\
\text { gestión de una política pública }\end{array}$ \\
\hline & $\begin{array}{l}\text { Con la ciudadanía } \\
\text { (agentes sociales y } \\
\text { económicos) }\end{array}$ & $\begin{array}{l}\text { Involucra agentes externos (ciudadanía) en la gestión } \\
\text { pública en relación con una entidad gubernamental }\end{array}$ \\
\hline & Mixta & Involucra a diversas agencias gubernamentales y a la \\
\hline & Precisa & $\begin{array}{l}\text { ciudadanía } \\
\text { Acorde a tareas y objetivos claramente definidos }\end{array}$ \\
\hline & Ambigua & Sin especificar tareas y objetivos \\
\hline
\end{tabular}




\begin{tabular}{ccc}
$\begin{array}{c}\text { Componentes } \\
\text { analíticos }\end{array}$ & Variables & Especificación \\
\hline $\begin{array}{c}\text { Control/ } \\
\text { Influencia } \\
\text { (toma de } \\
\text { decisión } \\
\text { incluyente) }\end{array}$ & $\begin{array}{c}\text { Mecanismos } \\
\text { (gubernamentales) } \\
\text { directos } \\
\text { Mecanismos } \\
\text { (gubernamentales) } \\
\text { indirectos } \\
\text { Estrategias (de los } \\
\text { agentes ciudadanos) } \\
\text { institucionales }\end{array}$ & $\begin{array}{c}\text { Permiten que los tomadores de decisión reciban } \\
\text { información de manera directa, mediante espacios } \\
\text { formalmente establecidos }\end{array}$ \\
& $\begin{array}{c}\text { Implica la recepción de información de manera } \\
\text { indirecta sin que haya espacios formales de } \\
\text { interacción }\end{array}$ \\
& $\begin{array}{c}\text { Siguen los canales formales para transmitir la } \\
\text { información a los tomadores de decisiones. Suele } \\
\text { ser una transmisión directa de información. Las } \\
\text { estrategias más comunes son la asesoría y el cabildeo } \\
\text { Siguen los canales informales para transmitir la }\end{array}$ \\
& $\begin{array}{c}\text { información a los tomadores de decisiones. Suele ser } \\
\text { una transmisión indirecta de información. Las más } \\
\text { comunes son: el activismo y la presión pública }\end{array}$ \\
& Se combinan estrategias institucionales y \\
& Mixta & extrainstitucionales para tratar de incidir en los \\
& & procesos decisorios
\end{tabular}

Fuente: Elaboración propia

La participación, impulsada desde el ámbito gubernamental o ciudadano y entendida como el ejercicio comunicativo de opiniones, puede ser directa o indirecta (Pitkin 1972, Isunza y Gurza 2010, Montes de Oca 2014). La primera modalidad sería más amplia porque requiere la presencia de todos los interesados (Goodin 2004). Empero, dependiendo de los mecanismos particulares (Font 2004), esta participación puede o no ser posible. Instrumentos de democracia directa como las consultas públicas y el referéndum favorecen esta presencia ampliada.

Las tecnologías de la información y comunicación también contribuyen a la participación directa online. Sin embargo, en mecanismos deliberativos su imposibilidad práctica la hace viable solo mediante la modalidad indirecta a través de "representantes virtuales" -es decir, aquellos que actúan a favor de intereses de un grupo o sector (Pitkin 1972: 173-176)- y que remite a la conformación de "públicos temáticos" (Font 2004: 25-26). Cabe señalar que esta participación tiene un carácter restringido (o elitista) porque solo involucra (de manera directa) a individuos informados y activos, especialistas en determinados temas. En este sentido, la participación también puede ser abierta o restringida. Es abierta cuando participa todo aquél que esté interesado; mientras que es restringida a aquellos que, por tener ciertas características, son invitados a participar.

Ahora bien, la colaboración (que se distingue de la participación porque involucra una tarea que sobrepasa el ejercicio de comunicación de opiniones, e implica articulación de actores para desarrollar tareas específicas en la 
gestión pública) se puede efectuar en tres ámbitos de interacción: entre agencias gubernamentales; entre el gobierno y la ciudadanía; o bien en una combinación de agentes internos y externos. Estas tareas pueden estar claramente definidas, lo que da un carácter preciso a la colaboración; o bien, pueden ser ambiguas $y$, por ende, difíciles de realizar.

Finalmente, la posibilidad de ejercer influencia en los procesos decisorios puede ser de manera directa, siguiendo los canales institucionales y aprovechando los mecanismos gubernamentales, mediante estrategias de consulta, asesoría o cabildeo; o bien, de forma indirecta y fuera de los canales institucionales con estrategias de confrontación, como son el activismo social y la presión pública, con las que se busca generar opinión pública tendiente a modificar la toma de decisión.

Antes de concluir la exposición del modelo heurístico resulta necesario destacar la distinción analítica que aquí se ha propuesto hacer entre participación e influencia. Ambas involucran una acción comunicativa, pero mientras la participación implica la emisión de una opinión (fundamentada en intereses, valores o evidencias específicas), la influencia consiste en la recepción (reconocimiento y aceptación) del mensaje emitido durante un ejercicio de participación. Cuando B emite un mensaje (opinión o información) sin que A lo reciba estamos hablando de participación (véase Figura 2 en contraste con la Figura 1 donde la línea punteada alude a la recepción y aceptación del mensaje). En esta relación A no cede control sobre su acción o toma de decisión, por lo que no hay un equilibrio entre control e influencia.

Figura 2: Participación

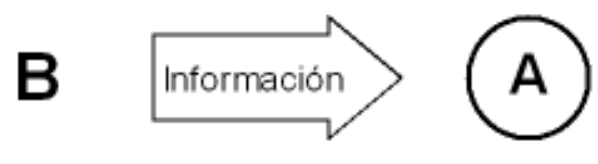

Fuente: Elaboración propia

\section{APLICACIÓN ANALÍTICA DEL MODELO: CONSEJOS CONSULTIVOS EN MÉXICO}

El modelo construido es útil para analizar formas aparentemente innovadoras de gobernar a fin de determinar si constituyen un modo diferente de relación entre gobierno y ciudadanía. Este es el caso, por ejemplo, de una innovación gubernamental que ha sido ampliamente criticada en la literatura especializada, particularmente para México: los 
consejos consultivos. Es decir, los espacios gubernamentales de participación donde interactúan agentes internos (de diversas dependencias) y/o agentes externos (ciudadanía) cuya función está orientada a incluir la voz ciudadana en los procesos gubernamentales y decisorios. Estos espacios han sido cuestionados debido a que no cumplen su objetivo principal -esto es, mejorar el diseño de políticas públicas con la opinión ciudadana-; por lo que son calificados como "intentos decorativos" cimentados en un ethos gubernamental basado en la simulación (Hevia e Isunza 2012, véase también Olvera 2009). Esto, porque fungen solo como instrumentos de legitimación política (Hevia e Isunza 2010); o bien, como instituciones opacas donde no existe distribución de poder (Hevia, Vergara-Lope y Ávila 2011).

$\mathrm{Al}$ aplicar este modelo en el análisis de consejos consultivos en México es preciso averiguar si la dependencia gubernamental facilita la información que los consejeros solicitan; si los integrantes del consejo producen información con valor público; y si ambas son de acceso abierto. También, considerando que los consejos consultivos son espacios gubernamentales de participación indirecta, debe identificarse su genealogía; esto es, el proceso que siguió su conformación y continuidad detectando la modalidad para ser integrado. Asimismo, se tiene que averiguar si el consejo está constituido solo por agentes gubernamentales, lo que implicaría una colaboración intergubernamental; si en él participan agentes externos (ciudadanos); o si es mixto.

Finalmente, y considerando que los consejos consultivos aluden a mecanismos gubernamentales que de manera institucional y directa favorecerían la influencia de agentes intersectoriales y externos en la toma de decisión, deben analizarse las estrategias orientadas a incidir en los procesos decisorios. Ahora bien, antes de abordar la aplicación de este modelo en tres órganos consultivos, a continuación, se presenta la "trastienda de la investigación” (Wainerman y Sautu 2011) de los casos analizados.

\section{Del Diseño METOdológico y los CaSos analizados}

A manera de ejercicio, se aplica el modelo construido para analizar tres órganos consultivos que fueron objeto de una investigación más amplia, realizada entre 2011 y 2015, y que se interesó en analizar la genealogía, conformación, operación y resultados de tres espacios de consulta de agencias mexicanas de regulación económica y social: 1) en telecomunicaciones; 2) normalización económica; y 3) protección al consumidor.

El proceso de investigación siguió una metodología cualitativa 
adaptando las pautas del método etnográfico. Es decir, la imbricación no lineal, sino flexible e iterativa, de tres momentos metodológicos: uno de documentación, otro destinado al trabajo de campo y uno más para el trabajo de gabinete. Siguiendo los criterios de calidad de la metodología cualitativa (Valles 1999), en este proceso se triangularon técnicas para la construcción de evidencia empírica: revisión documental, observación y entrevistas. A partir de esta evidencia fue posible aplicar el modelo heurístico aquí propuesto.

Los casos a partir de los cuales a continuación se discute la aplicación del modelo son: 1) el consejo consultivo de la extinta Comisión Federal de Telecomunicaciones (Cofetel); 2) el consejo consultivo de la Procuraduría Federal del Consumidor (Profeco); y 3) el Comité Consultivo Nacional de Normalización de Seguridad al Usuario, Información Comercial y Prácticas de Comercio (adscrito a la Secretaría de Economía).

El primero, constituido en 1996 cuando se creó Cofetel, fue modificado en 2015 después de que la Comisión fuera sustituida por el Instituto Federal de Telecomunicaciones; el segundo sigue operando, aunque de manera descentralizada en las oficinas estatales de Profeco; mientras que el tercero continúa su operación sin cambios relevantes. El consejo de Profeco fue creado en 2005; mientras el comité consultivo de normas data de 1992, cuando se emitió la Ley Federal de Metrología y Normalización. Los tres son mecanismos de la administración pública federal orientados a incluir la voz de agentes externos en los procesos gubernamentales y decisorios relacionados con la regulación de tipo económico y social. Al respecto cabe mencionar que los consejos/comités consultivos, por definición, deberían ser mecanismos con participación externa, no obstante, en la práctica hay casos que muestran una conformación estrictamente gubernamental ${ }^{13}$.

Los casos analizados son relevantes porque cristalizan la confrontación de intereses sociales, políticos y económicos. Ello se explica porque los tres operan en el terreno de la regulación estatal sobre el mercado. Por una parte, con la regulación económica que es la limitación gubernamental impuesta a los agentes económicos para mejorar las condiciones competitivas del mercado; y, por la otra, con la regulación social que es la limitación gubernamental impuesta, también, a los agentes oferentes del mercado, pero que está orientada a "proteger el interés público" en áreas con "problemas de información o externalidades negativas", específicamente,

13 Esto fue lo ocurrido en la etapa 2002-2005 del consejo consultivo de Cofetel, el cual fue de carácter exclusivamente gubernamental. En palabras de una excomisionada, "parecía más bien una comisión intersecretarial y no un consejo consultivo" (entrevista online realizada el 8 de mayo de 2012 desde la ciudad de México). 
sobre procesos productivos relacionados con alimentación o medicamentos (Cofemer 2011, véase también IMCO 2010).

De manera particular se analizó a profundidad el trabajo de los dos consejos y el comité en periodos específicos, contemplando, empero, como parte de su genealogía, la operación desde su primera conformación. Específicamente, se investigó el último CCCft, el cual operó entre 2011 y 2013; el CCC en el periodo 2009-2011; y el CCNN en el periodo 20112013.

Considerando que los casos conforman una "muestra significativa" (Guber 2004) -no probabilística-, la selección de los casos siguió como criterio la forma de organización ${ }^{14}$ :

- El CCCft se reunía cuatro veces al año en sesiones ordinarias presididas por un integrante del mismo consejo, quien tenía el apoyo operativo de un Secretario Técnico, único funcionario de Cofetel que asistía -con voz pero no con voto- a las sesiones ${ }^{15}$. En los periodos intermedios, los consejeros, organizados en grupos temáticos, trabajaban los documentos (basados en diagnósticos y opiniones técnicas) que conformarían sus recomendaciones finales sobre los temas que ellos consideraran relevantes.

- $\quad$ En contraste, el CCC se reunía tres veces al año en sesiones ordinarias presididas por el titular de la dependencia (el Procurador), con el apoyo operativo de un Secretario Técnico integrante también de la estructura burocrática. En estas sesiones los miembros del consejo eran informados sobre las decisiones tomadas, así como por las acciones realizadas por Profeco. Si bien los consejeros podían integrar temas a la agenda establecida por la dependencia, era la Procuraduría quien establecía los puntos a tratar durante la sesión. Estas sesiones, a diferencia de las del CCCft, se caracterizaban por la discusión en vivo sobre los temas que interesaban a las organizaciones participantes. Esto significa que, en general, los consejeros no elaboraban previamente y en conjunto documentos de trabajo con opiniones analizadas fuera de la sesión.

- $\quad$ Finalmente, el CCNN tiene una lógica de trabajo diferente primero

14 La muestra cualitativa o significativa se basa en atributos social y culturalmente relevantes, según el objeto de estudio (Guber 2004: 122-123).

15 Cabe mencionar que, en algunas sesiones y a petición de los propios consejeros, se invitó a algún funcionario de la comisión para que presentara la postura institucional sobre algún tema en específico. 
por su carácter resolutivo y no solo consultivo. Este comité operaba anualmente en cuatro sesiones ordinarias y las extraordinarias necesarias. En estas sesiones el comité se reunía para aprobar los anteproyectos de normas; así como para conocer las observaciones realizadas en los grupos de trabajo o bien en las consultas públicas a las Normas Oficiales Mexicanas (NOM). La deliberación técnica y el análisis sobre temas específicos se efectuaban en los grupos de trabajo. Las sesiones ordinarias del CCNN eran presididas por funcionarios de la Secretaría de Economía (en las figuras de Presidente y Secretario Técnico). En contraste, los grupos de trabajo eran presididos por un integrante del comité y a sus reuniones asistía el Secretario Técnico del comité.

Considerando estas diferencias en su operación, a continuación, se presentan los resultados que arroja la aplicación del modelo heurístico a fin de valorar si estos espacios conforman una nueva forma gestión pública.

\section{DisCUSIÓN SOBRE SU APLICACIÓN}

De manera ideal un consejo consultivo debería funcionar como un mecanismo gubernamental para promover la transparencia, participación, colaboración e influencia. En esto habría que considerar, empero, que la participación en estos espacios usualmente es restringida a ciudadanos seleccionados por el propio organismo gubernamental; o, en su defecto, a ciudadanos que se autoproponen o son propuestos por organizaciones específicas, pero que son avalados, en última instancia, por la autoridad.

En el primer tipo de conformación, con ciudadanos seleccionados por la agencia gubernamental, se ubica el CCC y el CCCft. En los dos es la agencia gubernamental (Profeco y Cofetel, respectivamente) la que designa a sus integrantes; ello difiere del otro caso. En el CCNN las organizaciones interesadas -empresariales, académicas o de consumidores- presentan una solicitud ante la Dirección General de Normas (DGN) de la Secretaría de Economía, quien acepta o niega la solicitud (véase Tabla 3). 
Tabla 3: Resultados de la aplicación del modelo heurístico en tres casos CCCft CCC CCNN

\begin{tabular}{cccc}
\hline Transparencia & $\begin{array}{c}\text { - Reactiva } \\
\text { - Enfocada } \\
\text { - Abierta }\end{array}$ & $\begin{array}{c}\text { - Reactiva } \\
\text { - Enfocada }\end{array}$ & $\begin{array}{c}\text { - Reactiva } \\
\text { - Enfocada } \\
\text { - Restringida }\end{array}$ \\
\hline Participación & $\begin{array}{c}\text { - Indirecta } \\
\text { - Restringida } \\
\text { - Gubernamental }\end{array}$ & $\begin{array}{c}\text { - Indirecta } \\
\text { - Restringida } \\
\text { - Gubernamental }\end{array}$ & $\begin{array}{c}\text { - Indirecta } \\
\text { - Restringida }\end{array}$ \\
\hline Colaboración & - Mixta & - Mixta & - Mixta \\
\hline Influencia & - Ambigua & - Precisa & - Precisa \\
& $\begin{array}{c}\text { - Mecanismo } \\
\text { indirecto }\end{array}$ & $\begin{array}{c}\text { - Mecanismo } \\
\text { indirecto }\end{array}$ & - Mecanismo directo \\
& - Estrategias mixtas & - Estrategias mixtas & - Estrategias mixtas
\end{tabular}

Fuente: Elaboración propia

Ahora bien, el manejo de la información -pudiendo ser abierto o restringido- depende de la disposición de información con alto o bajo valor público a petición de los consejeros o a propuesta de la dependencia gubernamental. Como se aprecia en la Tabla 3, en los tres casos analizados la transparencia es reactiva y enfocada debido a que obedece a la petición de los integrantes del consejo/comité sobre aspectos puntuales que interesa analizar. En lo que difieren es en el carácter abierto o restringido de la información generada. Mientras el CCCft sigue una pauta abierta en el manejo de la información recibida y trabajada en su seno, esto no ocurre con los otros dos casos. Tanto el CCC como el CCNN tienen una política restrictiva para hacer pública la información trabajada.

Los integrantes del último CCCft establecieron, en su momento, que las sesiones debían ser abiertas (primero fueron transmitidas vía streaming y luego recibieron la asistencia de todo público interesado), además de que publicaban en un micrositio de Internet las recomendaciones que le hacían a Cofetel. Esta apertura se reforzaba con la difusión que algunos de sus integrantes les daban a los documentos trabajados; de manera particular este era el caso de quienes integraban el sector de organizaciones sociales: en sus portales de Internet hacían eco del trabajo del consejo. Esto último se constituye también en un recurso para algunas de las organizaciones sociales que integraban el CCC. Pese a que Profeco no promovía la apertura de la información trabajada en su consejo consultivo ${ }^{16}$. algunas de las organizaciones que ahí participaban sí lo hacían. En esto también cabe

16 Si bien el CCC cuenta con un micrositio en Internet (http://ccc.profeco.gob.mx/), en 2013 este estaba desactualizado (mostraba información de 2010), en 2015 se reestructuró y desde 2016 no se actualiza. 
mencionar una distinción más entre ambos consejos. Mientras el CCC trabajaba con la información que Profeco les brindaba, el CCCft construía sus propios documentos de trabajo haciendo investigación por su cuenta.

Esto último está relacionado con el siguiente componente analítico. El CCC y CCNN tienen una colaboración precisa porque en cada uno, aunque sea de manera restringida, se planteaba puntualmente qué tareas debía desempeñar el consejo/comité. El CCC se enfocaba en emitir opiniones sobre los temas que Profeco establecía; y en el CCNN se concentraban los trabajos en la revisión o emisión de determinadas normas oficiales. En contraste, en el CCCft había mayor libertad en construir la agenda; los consejeros definían qué temas ocuparían su trabajo colegiado. Empero, esta modalidad tenía como limitante el desfase entre las recomendaciones realizadas y el trabajo de Cofetel; ello dificultaba la colaboración. En este caso los consejeros criticaban que sus recomendaciones no solo no fueran incluidas en las discusiones de la autoridad, sino que no fueran siquiera leídas por los comisionados ${ }^{17}$. Respecto a la colaboración cabe mencionar que los tres espacios de consulta (en los periodos puntualmente analizados) operaban con agentes gubernamentales de distintas dependencias, además de aquellos relacionados con sectores sociales y económicos específicos.

El CCCft, en su última etapa (2011-2013), estuvo conformado por cinco sectores: gubernamental, industria, consultores, academia y organizaciones sociales; teniendo mayor presencia los tres últimos. En el CCC también estaban representados varios sectores: gubernamental, academia y organizaciones de consumidores. Cabe mencionar que desde 2012 este consejo alberga también miembros que representan la voz de la industria. Finalmente, el CCNN ha estado integrado por organizaciones empresariales y de comerciantes, así como por instituciones académicas y por representantes de diversas dependencias del gobierno federal. Empero, es relevante desatacar que en 2011 hubo un intento del Secretario Técnico del comité, a cargo del entonces Director de Normalización de la Secretaría de Economía, para integrar a miembros de organizaciones que representaran los intereses de consumidores y usuarios. Esta participación prosperó entre 2011 y 2012 cuando tres organizaciones sociales fueron apoyadas (con gastos de viáticos) para asistir a las sesiones de trabajo; situación que cambió, desde 2013, con la nueva administración federal ${ }^{18}$.

17 La relación de este consejo con Cofetel estaba mediada por la figura del Comisionado Presidente, por lo que se decía que era el consejo consultivo del Presidente y no de toda la comisión.

18 Información de entrevista realizada el 2 de julio de 2014 en Guadalajara, Jalisco. 
Finalmente, considerando el último componente analítico del modelo podemos decir que a pesar de que los tres tienen una misión consultiva, varían por el carácter resolutivo de uno de ellos. Mientras el CCNN es un mecanismo de influencia directa debido a que las opiniones generadas en grupos de trabajo con especialistas técnicos alimentan los proyectos de norma que después son aprobados por la autoridad; los otros dos operan como mecanismos indirectos de influencia.

El CCCft y el CCC son órganos de consulta de agencias gubernamentales que en sí mismas tienen baja capacidad resolutoria sobre los procesos decisorios. De hecho, esta fue una de las razones por las que se modificó la legislación en radiodifusión y telecomunicaciones a fin de crear una agencia reguladora con mayor capacidad de control sobre el mercado, y con mayor autonomía frente a otras dependencias gubernamentales. Antes de esta modificación, Cofetel era criticada por operar como una "doble ventanilla", supeditada a las decisiones tomadas en la Secretaría de Comunicaciones y Transportes (SCT) ${ }^{19}$ Por su parte, pese a que Profeco es el órgano encargado de proteger los derechos de los consumidores, sus funciones están mermadas porque tal protección está fragmentada en diversas dependencias (sector financiero, sector salud, alimentos y servicios hospitalarios). Asimismo, sus atribuciones legales le permiten actuar solo frente a denuncias, estableciendo sanciones ex post, es decir, cuando los intereses de los consumidores ya fueron vulnerados ${ }^{20}$.

Cabe mencionar que frente a la baja capacidad de influencia de estos mecanismos institucionales (CCC y CCCft) las organizaciones ciudadanas (sociales y empresariales) suelen emplear otras estrategias institucionales (como el lobbying), o extrainstitucionales (como el activismo social y la presión pública). Esto se ilustra, por ejemplo, con la baja participación del sector industrial en el CCCft. De manera particular y considerando lo dicho por algunos de los consejeros entrevistados, esto se debía a que, por una parte, la Comisión no consideraba las opiniones de su consejo consultivo para tomar decisiones y, por la otra, a que el peso del proceso decisorio estaba en otra parte, esto es, en la SCT ${ }^{21}$. Entonces, los representantes de la industria optaban por utilizar otras estrategias de influencia, de

19 Información de entrevistas realizadas el 3 de mayo y el 12 de junio de 2012 en la Ciudad de México.

20 Información de entrevista realizada el 25 de enero de 2012 en la Ciudad de México.

21 Entrevistas realizadas el 4 de mayo, así como el 12 y 13 de junio de 2012 en la Ciudad de México. 
manera particular el cabildeo o lobbying en el Ejecutivo, vía la SCT ${ }^{22}$, o en el Legislativo; o bien con presión pública mediante desplegados en los medios impresos (prensa) o a través de los conductores de programas de radio y televisión.

En esto también se pueden mencionar las estrategias utilizadas por organizaciones sociales. En las entrevistas realizadas, los integrantes de organizaciones y académicos participantes en el CCC coincidieron en que los consejos consultivos eran una fórmula "agotada" o "insuficiente" para incidir en la toma de decisión pública ${ }^{23}$, razón por la cual se opta por otras estrategias de influencia. De manera particular esto se puede ilustrar con campañas y protestas públicas de activistas, integrantes del CCC, en contra de la venta y publicidad en escuelas de la comida "chatarra" (con bajo contenido nutricional y alto contenido calórico); o bien, con aquellas realizadas en contra del no etiquetado de productos con OGM.

Ahora bien, estas estrategias indirectas también son empleadas para compensar los diferenciales de poder de quienes conforman espacios como los aquí analizados (Fung y Wright 2003). Ese es el caso del CCNN, donde la industria -según se constató en la observación y las entrevistas- tenía mayor presencia y capacidad de influencia. De manera particular, durante la elaboración de la NOM sobre eficiencia energética las organizaciones de consumidores participantes resarcieron la falta de conocimientos técnicos conformando una red con otras organizaciones aliadas que colaboraron en la presentación de argumentos especializados. Al respecto cabe enfatizar que la participación del sector consumidores y usuarios en este espacio fue excepcional; por lo general -considerando los comentarios de los integrantes entrevistados- los grupos de trabajo suelen estar integrados por tres sectores: comercial, industrial y gobierno; incorporándose ocasionalmente el sector académico. Salvo el intento por promover la participación de organizaciones de consumidores en este comité, la "voz de los consumidores" suele estar a cargo del representante de Profeco.

En suma, la aplicación de este modelo permite caracterizar los tres casos a partir de su participación gubernamental, indirecta y restringida. Asimismo,

$22 \mathrm{Al}$ respecto, uno de los consejeros entrevistados afirmó que para los operadores era más fácil hacer lobbying en la SCT, porque había que convencer solo al secretario; mientras que en Cofetel había que convencer a los cinco comisionados (entrevista realizada el 13 de junio de 2012 en la Ciudad de México).

23 Entrevistas realizadas el 12 de junio de 2012 y el 22 de mayo de 2014 en la ciudad de México; así como el 1 y 2 de julio de 2014 en la ciudad de Guadalajara. 
permite ubicar las modalidades para generar información y hacerla pública; así como las formas en que se lleva a cabo la colaboración. El modelo también ha sido útil para identificar los mecanismos gubernamentales orientados a favorecer (o no) la influencia de agentes externos, así como las estrategias de estos para complementar su capacidad de incidir en los procesos gubernamentales y decisorios.

En los casos analizados vimos cómo las organizaciones ciudadanas (sociales y empresariales) aprovechan estos espacios de informaciónparticipación-colaboración para tratar de influir en los procesos gubernamentales y decisorios, pero también para reforzar su presencia pública y la construcción de redes y alianzas organizacionales; con lo que complementan sus otras estrategias de influencia (en particular, el lobbying y el activismo social).

\section{CONCLUSIÓN: ¿LOS CONSEJOS CONSULTIVOS SON UNA NUEVA FORMA DE GOBERNAR?}

Por definición, los consejos consultivos son un mecanismo de participación ciudadana restringida e indirecta. Ello, de entrada, le imprime una particularidad a cualquier análisis. No podemos exigirle a este mecanismo de participación institucionalizada (Saltalamacchia y Ziccardi 2005) elementos que no corresponden con su naturaleza. Ello nos remite a la crítica de la gobernanza neoliberal en el sentido de que con ella se sustituye la participación popular por una "participación selectiva de interesados" (Santos 2007: 37). Los consejos consultivos no agotan las posibilidades de participación y, como hemos visto, tampoco las sustituyen. Los agentes sociales y económicos buscan otros canales para incidir en la toma de decisión pública cuando encuentran que sus propuestas no son retomadas por el gobierno a través de estos canales.

El que se abran espacios de información-participación como los consejos consultivos puede ser, dependiendo del caso, un paso orientado a gestar una nueva forma de gobierno; aunque también su plena operación -cristalizada en la colaboración y la influencia- puede verse impedida por la falta de cambios organizacionales y culturales al interior de la administración pública y de la propia ciudadanía. Esto significa que ambas partes no estén dispuestas a colaborar y, lo que es más, a promover una decisión incluyente. Empero, por sí mismos, los consejos consultivos y su participación restringida no implican cooptación de otras formas de participación (ampliada o restringida). Son un mecanismo institucionalizado que se complementa con otras estrategias formales e informales de participación orientadas a incidir en las decisiones públicas. Quienes participan en estos 
consejos también recurren a protestas públicas, formación de redes de defensa, cabildeo o campańas publicitarias para amplificar su capacidad de influencia.

Habiendo hecho esta precisión vale la pena reflexionar ahora sobre los resultados mostrados con la aplicación del modelo heurístico construido. Los consejos consultivos analizados son espacios de transparencia y participación. En ellos la autoridad informa a sus miembros sobre decisiones ya tomadas (CCC); o bien, mediante la deliberación, se construye información con valor público. Esta información generada de manera expresa con la intención de incidir en la toma de decisión pública, puede ser ignorada por la autoridad (CCCft); o bien, puede ser retomada para los procesos decisorios $(\mathrm{CCNN})$.

Los tres casos se caracterizan por tener una conformación multisectorial, lo que hace que la colaboración sea mixta. La colaboración gobiernociudadanía es puntual para dos casos ( $\mathrm{CCC}$ y $\mathrm{CCNN}$ ) en los que la autoridad designa las tareas específicas a desarrollar. Ello no ocurría con el CCCft; empero, ahí, la colaboración entre los consejeros permitía un trabajo en grupo que se tradujo en la elaboración conjunta de recomendaciones muy diversas sobre los temas que, si bien, estaban desfasadas respecto a la agenda de trabajo de Cofetel, sí eran relevantes en la discusión pública sobre la regulación en el sector. No obstante este empeño, el desfase respecto a los tiempos de Cofetel hacía que las recomendaciones no coincidieran con los temas discutidos en el pleno de la comisión, lo que minaba la posibilidad de influir en los procesos decisorios.

Sobre este último componente analítico, equilibrio entre el control y la influencia en la toma de decisión pública, es que los tres casos varían de manera puntual. Solo en el CCNN se puede hablar de posibilidad de influencia. Los grupos de trabajo del Comité Consultivo de Normalización son espacios no solo de información, participación y colaboración; por su carácter resolutivo y no solo consultivo, ahí se toman decisiones por consenso que son recogidas por la Secretaría de Economía para elaborar o modificar normas específicas. En este caso, la colaboración y posibilidad de influencia están establecidas formalmente en la reglamentación sobre normalización y estandarización; aunque no así, la obligación de que esté representado el sector de consumidores a través de organizaciones sociales que resguarden esos intereses frente a los de la industria; ello dependió -según palabras de un entrevistado- de "la buena disposición" del funcionario en turno.

Lo anterior se presenta de manera más clara en los otros dos casos, 
donde los reglamentos de las agencias regulatorias (Profeco y Cofetel) no estipulan la relación que debe tener la autoridad con su respectivo consejo consultivo. En estos casos, el establecimiento de un órgano de consulta cumple con lo establecido en el decreto de creación de cada dependencia; empero, la forma en que opera el consejo consultivo queda abierta a la discrecionalidad del funcionario en turno. Esto se aprecia en los intentos fallidos que tuvo Cofetel para conformar su órgano de consulta entre 1996 y 2010. No fue -como lo expresaron varios de los entrevistados- sino hasta que el último Comisionado Presidente "se tomó en serio" este consejo, que se pudo integrar un grupo que además de tener continuidad en el trabajo realizado, se caracterizó por una alta productividad, al emitir en promedio una recomendación mensual.

Esta discrecionalidad también se observa en el trabajo del CCC cuya operación, en opinión de una de sus integrantes, siguió los vaivenes políticos de la institución: Primero, con las designaciones de nuevos funcionarios después de la alternancia en el gobierno federal de 2012; y luego con diversos escándalos públicos relacionados con la corrupción de algunos funcionarios. Frente a estos episodios -según lo precisaron dos consejeras entrevistadas-, Profeco cerró las puertas para que se celebraran las sesiones de su consejo consultivo en 2012 y 2013.

Esto último refleja una actitud del gobierno frente a la ciudadanía que también se aprecia en el CCCft. En ambos casos (CCC y CCCft) hay un dejo de desconfianza de los funcionarios públicos frente a la voz de la ciudadanía. Ello genera un círculo vicioso de crítica, desconfianza y conflicto que merma los esfuerzos de acercamiento y, por tanto, de colaboración e influencia. Funcionarios de Cofetel descalificaban al consejo consultivo por considerarlo el "juguetito del Comisionado Presidente" mientras que los funcionarios de Profeco "tenían que aguantar" las sesiones de su consejo consultivo, donde las organizaciones de consumidores "solo iban a quejarse" 24 . Cabe mencionar que esta actitud también se presenta en el CCNN. Por una parte, de los funcionarios hacia los representantes industriales, a quienes se les frena para evitar la captura de la deliberación; $y$, por la otra, de los industriales hacia los representantes de organizaciones sociales a quienes se les critica sobre su representatividad cuestionándoles a qué y cuántos consumidores representaba su opinión ${ }^{25}$.

24 Información de entrevista realizada el 5 de junio de 2012; así como de la observación participante realizada en Profeco entre febrero y agosto de 2012 y en un taller sobre telecomunicaciones el 15 y 16 de mayo de 2013 en la ciudad de Oaxaca.

25 Información de entrevista realizada en la ciudad de Guadalajara, 1 de julio de 2014. 
En suma, el análisis realizado muestra que si bien hay avances en la apertura de espacios que propician la transparencia y la participación, persiste una actitud gubernamental de recelo frente a los agentes externos (sociales y económicos), lo cual dificulta una agencia pública basada en la colaboración y en el equilibrio entre el control gubernamental y la influencia externa en los procesos decisorios. La interacción pública en estos espacios está marcada por la confrontación de intereses, más que por una lógica armónica y de relaciones horizontales.

Si bien hay buenas intenciones de algunos funcionarios que buscan cumplir con las transformaciones funcionales (lo cual, a su vez, favorece cambios comportamentales); los casos analizados también cristalizan resistencia a la apertura gubernamental, haciendo de estas innovaciones gubernamentales mecanismos incompletos, al no favorecer una agencia pública fundamentada en el equilibrio entre control e influencia. Falta entonces, consolidar las transformaciones organizacionales que condensen una nueva forma de gobernar.

Esto último tal vez se cristalice con los cambios que dos de los consejos analizados siguieron después de 2015. En particular, el consejo consultivo en materia de telecomunicaciones (una vez que se instalara el Instituto Federal de Telecomunicaciones, IFT) promovió modificaciones operativas para favorecer mayor coordinación entre el consejo y la agencia reguladora. Desde entonces los consejeros se coordinan con personal administrativo del IFT para gestionar las recomendaciones y prever temas de su agenda de trabajo. Asimismo, desde 2015 el Consejo Consultivo del Consumo procuró descentralizar sus actividades en consejos estatales, mientras que el consejo central disminuyó el número de miembros. Ello podría redundar en una estrategia más certera para gestionar una gestión pública participativa basada en los principios del gobierno abierto, las innovaciones democráticas y la gobernanza.

No obstante estas modificaciones, la moneda sigue en el aire. Además, con el cambio de gobierno federal en 2018 se vislumbran nuevos rumbos en la gestión pública mexicana. Será materia de otros análisis valorar si la gestión pública sigue apuntalando la participación ciudadana con principios y prácticas de control social y descentralización del poder; o si, en un giro invertido, retrocede a un proceder autoritario, cerrado y opaco. 


\section{REFERENCIAS}

Aguilar, L. (2006). Gobernanza y gestión pública. México: Fondo de Cultura Económica.

Alonso, S., Keane, J. y Merkel, W. (2011). Editor's introduction: Rethinking the future of representative democracy. En S. Alonso, J. Keane y W. Merkel (Eds.), The future of representative democracy. Nueva York: Cambridge University Press.

Arellano, D. y Cabrero, E. (2000). Introducción. En Arellano, D, y Cabrero, E. (Eds.), Reformando al gobierno. Una visión organizacional del cambio gubernamental. México: CIDE/Miguel Ángel Porrúa.

Arellano, D. y Amaya, L. (2000). Cambio en organizaciones gubernamentales: innovación y complejidad. En Arellano, D, y Cabrero, E. (Eds.), Reformando al gobierno. Una visión organizacional del cambio gubernamental. México: CIDE/Miguel Ángel Porrúa.

Cabrero, E. y Arellano D. (1993). Análisis de innovaciones exitosas en organizaciones públicas. Una propuesta metodológica. Gestión y Politica Pública, II (1), 59-86.

Calderón, C. (2012). Por qué un gobierno abierto. En Concha G. y Naser, A. (Eds.), El desafio hacia el gobierno abierto en la hora de la igualdad. Santiago de Chile: CEPAL.

Cameron, M., Hershberg, E. y Sharpe, K. (Eds.) (2012). Nuevas instituciones de democracia participativa en América Latina. México: FLACSO.

Campos, E. y Corojan, A. (2012). El estado del arte del gobierno abierto: promesas y expectativas. En Hofmann, A. Ramírez, A y Bojórquez, J.A. (Eds.), La promesa del gobierno abierto. México: InfoDf.

Cerrillo, A. (2005). Gobernanza hoy: Introducción. En Cerrillo, A. (Coord.), La gobernanza hoy: 10 textos de referencia. Madrid: Instituto Nacional de Administración Pública.

Comisión Europea (2001). La gobernanza europea. Un libro blanco. Bruselas: Unión Europea.

Comisión Federal de Mejora Regulatoria (Cofemer) (2011). Fortaleza institucional de los reguladores económicos en México (Documentos 
de Investigación en Regulación No. 2011-07). México: Cofemer/ Secretaría de Economía.

- (2012). Gobernanza regulatoria. En Diplomado en regulación económica (paquete didáctico). México: Cofemer/Latin-Reg.

Culebro, J. (2000). Cambio estructural. En Arellano, D. y Cabrero, E. (Eds.), Reformando al gobierno. Una visión organizacional del cambio gubernamental. México: CIDE/Miguel Ángel Porrúa.

Del Castillo, A. (2000). Problemas en la acción gubernamental: organizaciones y redes de actores. En Arellano, D. y Cabrero, E. (Eds.), Reformando al gobierno. Una visión organizacional del cambio gubernamental. México: CIDE/Miguel Ángel Porrúa.

Edelman, M. (1967). The Symbolic Uses of Politics. Illinois: The University of Illinois.

Elias, N. (1982). Sociología Fundamental. Barcelona: Gedisa.

Emerson, R. (1962). Power-dependence relations. American Sociological Review, 27 (1) 31-41.

Font, J. (2004). Participación ciudadana y decisiones públicas: conceptos, experiencias y metodologías. En Ziccardi, A. (Coord.), Participación ciudadana y políticas sociales en el ámbito local. México: Instituto de Investigaciones Sociales-UNAM.

Foucault, M. (1979). Microfísica del poder. Madrid: La Piqueta.

. (1988). El sujeto y el poder. En Dreyfus, H y Rabinow, P. (Eds.), Michel Foucault: Más allá del estructuralismo y la hermenéutica. México: Universidad Nacional Autónoma de México.

Fung, A. y Wright, E. (2003). Countervailing power in empowered participatory governance. En Fung, A. y Wright, E. (Eds.), Deepening democracy. Institutional innovation in empowered participatory governance. Londres: Verso.

Goodin, R. (2004). Representing diversity. British Journal of Political Science, 3 (34), 453-468.

Grindle, M. (2000). Audacious reforms. Institutional invention and 
democracy in Latin America. Baltimore: The John Hopkins University Press.

Guber, R. (2004). El salvaje metropolitano. Reconstrucción del conocimiento social en el trabajo de campo. Buenos Aires: Paidós.

Güemes, M. y Ramírez, A. (2012). Gobierno abierto, reforma del Estado y modernización de la gestión pública: Alcances, obstáculos y perspectivas en clave latinoamericana. En Hofmann, A. Ramírez, A y Bojórquez, J.A. (Eds.), La promesa del gobierno abierto. México: InfoDf.

Hevia, F. (2012). ¿Cuándo y por qué funcionan los consejos consultivos? Patrones asociativos, voluntad política y diseño institucional en órganos colegiados de participación del Poder Ejecutivo Federal mexicano. En Zaremberg, G. Redes y jerarquias. Participación, representación y gobernanza local en América Latina. México: FLACSO/IDRC.

Hevia, F. e Isunza, E. (2012). Participación acotada: consejos consultivos e incidencia en política públicas. En Cameron, M. Hershberg, E y Sharpe, K. (Eds.), Nuevas instituciones de democracia participativa en América Latina. México: FLACSO.

Hevia, F. e Isunza, E. (2010), La perspectiva de interfaz aplicada a las relaciones sociedad civil-Estado en México. En Olvera, A. (Ed.), La democratización frustrada. México: CIESAS/Universidad Veracruzana.

Hevia, F., Vergara-Lope, S. y Ávila, H. (2011). Participación ciudadana en México: consejos consultivos e instancias públicas de deliberación en el gobierno federal. Perfiles Latinoamericanos, 38, 65-88.

Instituto Mexicano para la Competitividad (IMCO) (2010). Regulación y competencia: Indicadores de competencia para América del Norte. México: IMCO/USAID. Disponible en http://imco.org.mx/images/ pdf/Documento_Final._29_septiembre_USaid_.pdf [17-08-2018].

Isunza, E. y Gurza, A. (2010). Precisiones conceptuales para el debate contemporáneo sobre la innovación democrática: participación, controles sociales y representación. En Isunza, E. y Gurza, A. (Eds.), La innovación democrática en América Latina. México: CIESAS/ Universidad Veracruzana.

Jordana, J. y Levi-Faur, D. (2004). The rise of the regulatory state in Latin America. En Working Paper Series, No. 61. Institute for Development 
Policy and Management, University of Manchester, Centre on Regulation and Competition. Disponible en http://www.dfid.gov.uk/ r4d/PDF/Outputs/RegComp/CRCwp61.pdf [17-08-2018].

Knoke, D. (1990). Political networks. The structural perspective. Nueva York: Cambridge University Press.

Kooiman, J. (Ed.) (1993). Modern governance. New government-society interactions. Londres: Sage. . . (2003). Governing as governance. Londres: Sage.

Laumann, E. y Knoke, D. (1987). The Organizational state. Social choice in national policy domains. Madison: The University of Wisconsin Press.

Lee, G. y Kwak, Y. H. (2011). An open government implementation model: Moving to increased public engagement. IBM Center for The Business of Government. Disponible en http://www.a51.nl/storage/pdf/An_ Open_Government_Implementation_Model.pdf. [19-11-2014].

Lehmbruch, G. (1992). Democracia consociacional, conflicto de clases y neocorporativismo, En Schmitter, P. y Lehmbruch G. (Coords.), Neocorporativismo I. Más allá del Estado y el Mercado. México: Alianza Editorial.

Mariñez, F. (2013). ¿Qué transparencia requiere el gobierno abierto? Revista de Gestión Pública, II (2), 303-333.

Martínez, R. (2012). Gobierno abierto: ¿Más gobierno o más ciudadanía? En Hofmann, A. Ramírez, A y Bojórquez, J.A. (Eds.), La promesa del gobierno abierto. México: InfoDf.

Mayntz, R. (2005). New challenges to govarnance theory. En Cerrillo, A. (Coord.), La gobernanza hoy: 10 textos de referencia. Madrid: Instituto Nacional de Administración Pública.

Montes de Oca, L. (2012). Influencia en la toma de decisión pública: Reto de la reorganización gubernamental. El caso del consejo consultivo de Cofetel. Revista Digital Estudios Interdisciplinarios de la Organización. Disponible en http://www.reio.com.mx/ docs $/ 6 . \% 20 I N F L U E N C I A \% 20$ EN\%20LA\%20TOMA\%20DE\%20 DECISION\%20PUBLICA.\%20VF.pdf [19-11-2014]. 
. (2014). ¿Innovaciones democráticas? Análisis del Consejo Consultivo de Telecomunicaciones en México. Revista Mexicana de Sociología, 76 (2), 287-320.

Moore, M. (2006). Creando valor público a través de asociaciones públicoprivadas. Reforma y Democracia, 34, 1-22.

Obama, B. (2009). Transparency and Open Government. Washington: The White House, Memorandum of January 21. Disponible en https:// obamawhitehouse.archives.gov/the-press-office/transparency-andopen-government [25-07-2019].

Olvera, A. (2009). La participación ciudadana y sus retos en México. México: Secretaría de Gobernación. Disponible en www.gobernacion. gob.mx/work/models/SEGOB/Resource/946/4/images/)Olvera_ Entregable_2.pdf> [23-09-2012].

Ornstein, N. y Elder S. (1978). Interest groups lobbing and policymaking. Washington, DC: Congressional Quarterly Press.

Osborne, T. y Gaebler, D. (1994). La reinvención del gobierno. La influencia del espiritu empresarial en el sector público. Barcelona: Paidós.

Ozslak. O. (2016). Gobierno abierto: el rumbo de los conceptos. En Luna, I. (Ed.), Gobierno abierto y el valor de la información pública. México: UNAM, Instituto de Investigaciones Jurídicas.

Pierre, J. (2000). Debating governance. Nueva York: Oxford University Press.

Pierre, J. y Peters, G. (2000). Governance, politics and the state. Nueva York: St. Martin's Press.

Pitkin, H. (1972). The concept of representation. Berkeley: University of California Press.

Programa de Naciones Unidas para el Dearrollo (PNUD) (2017). Análisis de la estructura y operación de los consejos consultivos para el desarrollo sustentable de la Semarnat 2011- 2016. México: Programa de las Naciones Unidas para el Desarrollo.

Rhodes, R.A.W. (2005). La nueva gobernanza: Gobernar sin gobierno. En Cerrillo, A. (Comp.), La gobernanza hoy: 10 textos de referencia. 
Madrid: Instituto Nacional de Administración Pública.

Saltalamacchia, H. y Ziccardi, A. (2005). Las ciudades mexicanas y el buen gobierno local: una metodología para su evaluación. Revista Mexicana de Sociología 67 (1) 31-97.

Santos, B. (2007). Más allá de la gobernanza neoliberal: el Foro Social Mundial como legalidad y política cosmopolitas subalternas. En Santos, B. y Rodríguez, C. (Eds.), El derecho y la globalización desde abajo: Hacia una legalidad cosmopolita. Barcelona/México: Anthropos/ UAMCuajimalpa.

Sartori, G. (2003). ¿Qué es la democracia? México: Taurus.

Schmitter, P. (1992). Continúa el siglo del neocorporativismo. En Schmitter, P. y Lemhbruch G. (Coords.), Neocorporativismo I. Más allá del Estado y el mercado. México: Alianza Editorial.

Shapiro, I. (2003). The state of democratic theory. Nueva Jersey: Princeton University Press.

Smith, G. (2009). Democratic innovations. Designing institutions for citizen participation. Nueva York: Cambridge University Press.

Torres, G. y Ramos, A. (2012). Nueva gestión de lo local. Desarrollo rural y construcción de sistemas agroalimentarios. En Lerner, B., Uvalle, R. y Moreno, R. (Coords.), Gobernabilidad y gobernanza en los albores del siglo XXI y reflexiones sobre el México contemporáneo. México: Instituto de Investigaciones Sociales, UNAM.

Valenzuela, R. (2014) Gobierno abierto en una perspectiva multinivel: Reflexiones entre la razón teórica y la innovación práctica. Revista de Gestión Pública, III (1), 163-197.

Valles, M. (1999). Técnicas cualitativas de investigación social. Reflexión metodológica y práctica profesional. Madrid: Síntesis.

Villoria, M. (2012). El gobierno abierto como subsistema de políticas: una evolución desde el institucionalismo discursivo. En Hofmann, A. Ramírez, A y Bojórquez, J.A. (Eds.), La promesa del gobierno abierto. México: InfoDf..

Wainerman, C. y Sautu, R. (Comps.). (2011). La trastienda de la 
investigación. Buenos Aires: Lumiere.

Weber, M. (1964). Economía y sociedad. México: Fondo de Cultura Económica.

Welp, Y. y Whitehead, L. (2011). Caleidoscopio de la innovación democrática en América Latina. México: Flacso/Nuffield College/Centre for Research on Direct Democracy.

Zurbriggen, C. y González, M. (2014). Innovación y co-creación: nuevos desafíos para las políticas públicas. Revista de Gestión Pública, III (2), 329-361.

Recibido: 05-02-2019

Aceptación de la versión final: 07-06-2019 